\title{
Spectroscopic Investigation of Degradation Reaction Mechanism in $\gamma$-Rays Irradiation of HDPE
}

\author{
Shiv Govind Prasad ${ }^{1,2, *(\mathbb{D})}$, Chhagan Lal ${ }^{1(\mathbb{D})}$, Kriti Ranjan Sahu ${ }^{3(\mathbb{D})}$, Abhijit Saha ${ }^{4(\mathbb{D})}$, Udayan De ${ }^{5(\mathbb{C})}$ \\ 1 Department of Chemistry, School of Basic and Applied Sciences, Harcourt Butler Technical University, Kanpur-208002 \\ UP India \\ 2 Department of Chemistry, Uttar Pradesh Textile Technology Institute, 11/208, Souterganj, Kanpur-208001 UP India \\ 3 Department of Physics, Bhatter College, Dantan, Paschim Medinipur- 721426 WB, India \\ 4 UGC-DAE Consortium for Scientific Research Kolkata Centre, III/LB-8 Bidhannagar, Kolkata-700 098, WB India \\ 5 Department of Physics, Egra SSB College, Egra 721429, Purba-Medinipur, W.B. India \\ * Correspondence: sgp_sinp@yahoo.com;
}

Received: 19.07.2020; Revised: 26.08.2020; Accepted: 28.08.2020; Published: 13.09.2020

\begin{abstract}
Radiation damage and reaction mechanism of product formation due to $\gamma$-irradiation in highdensity polyethylene (HDPE) have been studied by Fourier transform infrared (FTIR), UV-vis spectroscopic, and x-ray diffraction (XRD) techniques. $\mathrm{A} \mathrm{Co}^{60}$ gamma source (with a dose rate of 1.707 $\mathrm{kGy} / \mathrm{hr}$ ) has been used up to the total dose of $570 \mathrm{kGy}$. There are dose-dependent changes in the polymer. The optical band gap decreases with the increase of the $\gamma$-irradiation dose. Formations of unsaturation centers have been observed. FTIR observed that a lower dose of $\gamma$-irradiation induces the formation of an unsaturated ( $\mathrm{C}=\mathrm{C}-$ ) group and a ketone carbonyl group. Breaking of the $\mathrm{C}-\mathrm{H}$ bond is more frequent than the breaking of the $\mathrm{C}-\mathrm{C}$ bond in irradiated HDPE. Crosslinking dominates over chain scission (breaking of $\mathrm{C}-\mathrm{C}$ bond of the main chain) at a lower dose (100 kGy). There has been no significant influence of $\gamma$-irradiation on the crystalline structure, although crystalline size decreases. Mechanisms of the formation of alkyl, allylic, and polyenyl radicals have been investigated.
\end{abstract}

Keywords: FTIR; UV-Vis Spectroscopy; HDPE; XRD; Polymer; $\gamma$-radiation; polyenyl radical; Radiation damage; Reaction Mechanism.

(C) 2020 by the authors. This article is an open-access article distributed under the terms and conditions of the Creative Commons Attribution (CC BY) license (https://creativecommons.org/licenses/by/4.0/).

\section{Introduction}

Polyethylene is one of the most demanded thermoplastic. The commercial use of this material in fabrics, textiles, vehicles, food packaging, pharmaceutical, cosmetic industry, forensic work, space technology, and radiation shielding as composites and also in medical applications is well documented [1-9]. High-density polyethylene (HDPE) is a favorite in these applications. Plastic packaging materials and devices for medical applications are sterilized at room temperature by ionizing radiation like $\gamma$-ray in the air [10]. Few important applications of irradiation are crosslinking to improve cable insulations and plastic films and sterilization of medical items. A recent finding of fungal (Penicillium oxalicum and Penicillium chrysogenum) degradation [11] of HDPE and LDPE may help their bio-friendly disposal. Food materials are usually pre-packaged and then irradiated (often at a low dose rate) by gamma-ray to minimize microbial re-contamination [12]. So, polymers like HDPE face $\gamma$-irradiation in many of their important applications. To know their safe working life, $\gamma$-radiation damage to HDPE has been investigated here. This also helps the planning of radiation modification of different material properties in a controlled way. 
Properties of polymeric materials have been modified by using various types of ionizing radiations like heavy ions (in $\mathrm{MeV}$ range), light ions (in $\mathrm{keV}$ range), highly focused microscopic beams, high-intensity pulses, X-rays, gamma rays, electron, proton, and neutron beams [6]. The disintegration of HDPE has also been studied [13]. A crosslinked network between the polyolefin (LDPE) chains can enhance thermal and chemical resistance [14-15]. HDPE and their composite material are also used for various applications [16-19] like hip joint replacement [20]; bone substitute in medical applications [21]; engineering applications [2225]; and thermal stability [26-27]. The effects of the crystallinity of polyethylene with different densities using differential scanning calorimetry (DSC), shows that the crystallinity of polyethylene increases with an increase in density [28].

Polymer modification by $\gamma$-radiation is generally a superimposition of multiple mechanisms, including the interaction of the incident primary radiation playing the major role. The primary interaction may cause the initiation of secondary reactions. These changes in polymer depend mainly on radiation absorbed dose, polymer internal structure, chain length, and types of functional groups present in the polymer [29]. Gamma-ray modification [30-32] in thermal, tensile, and rheological properties, crystallinity, and heat of formation of HDPE, have been fairly well studied. This work showed that the property modification of polymeric materials mainly depends upon the formation of the crosslinking and chain scission. It has been established that during irradiation, there is a competition between crosslinking and chain scission, controlled by the structural properties of the polymer.

Product formation chemistry and mechanisms of chain scission and crosslinking in irradiated polymer, being relatively less investigated, an effort has been made to fill up the gaps and understand the degradation reaction mechanism.

Methods, such as Fourier transform infrared spectroscopy (FTIR), UV-Visible spectroscopy, and X-Ray Diffraction (XRD) were used to evaluate the changes in the chemical, physical, and structural properties of the material. A schematic mechanism of product formation is discussed. Observed experimental data on the behavior of gamma-irradiated HDPE have been interpreted in terms of absorbed dose.

\section{Materials and Methods}

\subsection{Materials and irradiation.}

High-density polyethylene (HDPE) polymer sheet with a thickness of $1 \mathrm{~mm}$ was procured from Good fellow Cambridge Limited, England, and used without further purification. It is typically $(70-80 \%)$ crystalline semi-opaque commodity thermoplastic. Samples of size $2 \mathrm{~cm} \times 3 \mathrm{~cm}$ have been manually cut from the HDPE sheet.

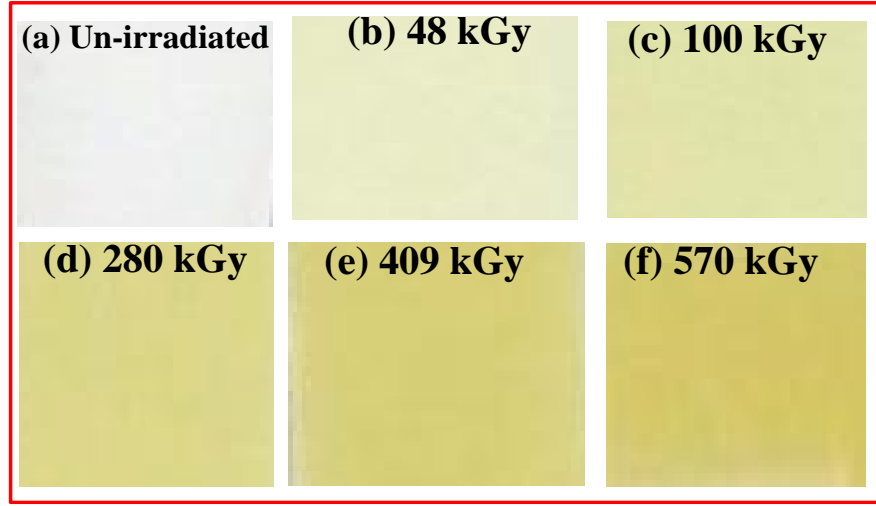

Figure 1. Colors of the un-irradiated and $\gamma$-ray irradiated sheets, with the $\gamma$-dose indicated in each picture. 
Most radiation damage studies in polymers use high dose rate $\gamma$-irradiation, while many applications of various polymeric materials involve a low dose rate. The dose rate influences the extent of radiation damage. So, we have selected a low dose rate of ${ }^{60} \mathrm{Co}$-gamma source $(1.707 \mathrm{kGy} / \mathrm{hr})$ in our irradiation at UGC-DAE CSR, Kolkata. Radiation at different doses up to the maximum dose of $570 \mathrm{kGy}$ has been done.

\subsection{Characterization.}

\subsubsection{X-ray diffraction.}

XRD measurements with PROTO, AXRD benchtop powder diffraction system have been undertaken by using monochromatic $\mathrm{CuK}_{\alpha}(\lambda=1.541 \AA)$ radiation over $2 \theta$ set from $10^{\circ}$ to $90^{\circ}$ with angular accuracy of $\Delta(2 \theta)=0.02^{\circ}$ and dwell time of 0.5 Second. The operating voltage and current were $27 \mathrm{kV}$ and $12 \mathrm{~mA}$, respectively. The polymer samples have been mounted one by one on a sample holder plate with clay to maintain the level of polymer film at the sample holder level. The sample holder spins during measurement for averaging. The distance between lattice planes (d-spacing) has been calculated from the X-Ray diffraction pattern using Bragg's equation:

$$
\mathrm{d}=\lambda / 2 \sin \theta
$$

where $\lambda$ is the wavelength of $\mathrm{x}$-ray used, and $2 \theta$ is the diffraction angle. In table 1 , the fullwidth at half maximum (FWHM) of the diffraction peaks were calculated by fitting the X-ray diffraction data, and the crystallite size $(L)$ was estimated by using the Scherrer equation:

$$
L=\mathrm{K} \lambda / \beta \cos \theta
$$

where K is Scherrer constant, which depends upon lattice direction and crystallite morphology, and $\beta$ is the FWHM.

\subsubsection{UV-Visible spectrometry.}

Optical absorption spectra of virgin sample and irradiated samples were measured in absorption mode with a step size of $0.5 \mathrm{~nm}$, in the wavelength range $200-1100 \mathrm{~nm}$, using a UVvis spectrophotometer (Lambda 360, India) at room temperature. Camera views of the color of the unirradiated and irradiated sheets are shown in Figure 1.

\subsubsection{FTIR Spectrometry.}

Fourier transforms infrared spectroscopy (FTIR) spectrum gives information on the structure, detailing the functional side group in polymer. The position of a given infrared absorption is expressed in terms of wavenumber $(v)$. The ordinary infrared region is 4000-667 $\mathrm{cm}^{-1}$ is important for the material. The region $12500-4000 \mathrm{~cm}^{-1}$ is called the near-infrared region, and the region $667-50 \mathrm{~cm}^{-1}$ the far-infrared. Generally, infrared spectra of material are plotted as percentage transmittance against wave number. The band intensity is either expressed in terms of absorbance (A), which is related to transmittance (T) [33] as follows:

$$
\mathrm{A}=2-\log _{10}(\% \mathrm{~T})
$$

FTIR spectra of virgin and irradiated samples were recorded in the wavenumber range $600 \mathrm{~cm}^{-1}$ to $4000 \mathrm{~cm}^{-1}$ in transmission mode using attenuated total reflection (ATR) facility in an Alpha-model FTIR spectrometer from Bruker, Germany. 


\section{Results and Discussion}

Traditional radiation chemistry study of polymers has mostly been done by irradiation with electron beams or gamma-rays, low linear energy transfer (low LET) radiations. Gammarays deposit radiation energy homogeneously, and the absorbed dose is expressed in terms of 'Gray' (Joules per kg) [1]. Some of the possible irradiation-induced changes are: scission or crosslinking of the polymer chains and covalent bond breaking. Formation of carbon clusters [2,34], the liberation of volatile species, and in some cases, the formation of the new chemical bond has can come into play. In the case of irradiation in air, oxygen reacts with radiationgenerated free radicals. Peroxide radicals formed in the process can undergo further reactions leading to chain scission, crosslinking, discoloration, the formation of hydroperoxides, carbonyl groups, acids, and low molecular weight products [35-36]. The general chemical structure of the high-density polyethylene is shown in Figure 2.

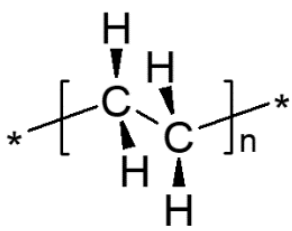

Figure 2. Chemical structure of HDPE.

\subsection{XRD measurement.}

X-ray diffraction (XRD) pattern of the unirradiated and irradiated HDPE sample is shown in Figure 3, having three characteristics peaks at $2 \theta$ values $21.42^{\circ}, 23.71^{\circ}$, and $36.08^{\circ}$ corresponding to the orthorhombic crystallite plane [110], [200] and [020], respectively [37].

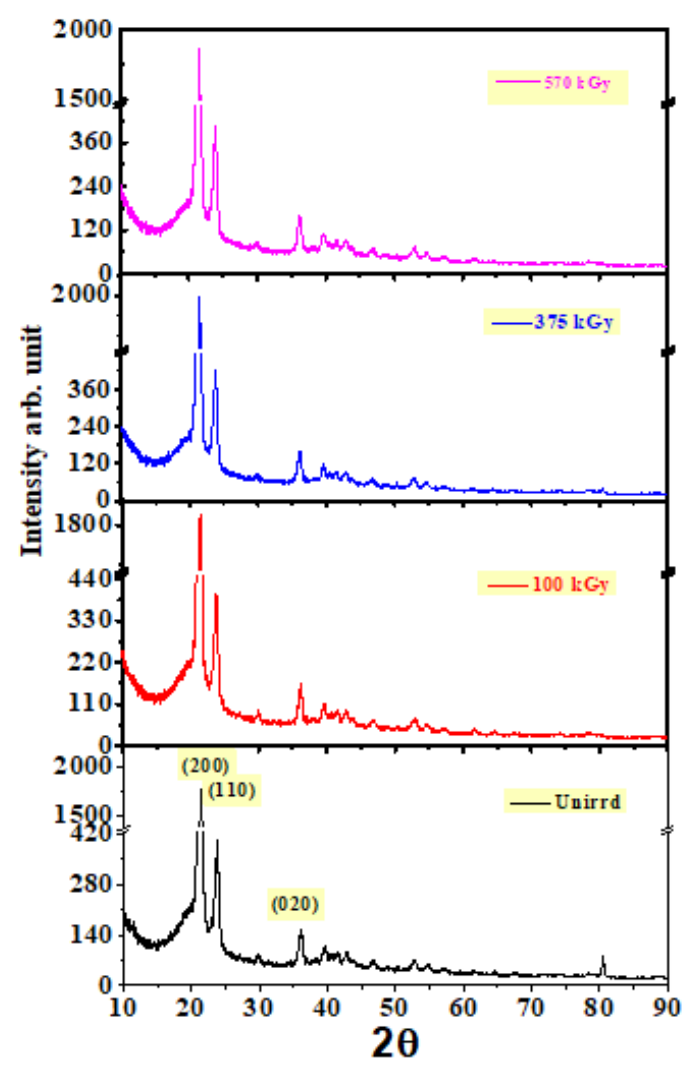

Figure 3.XRD spectra of HDPE sheets, virgin, and irradiated to different doses. 
Table 1. XRD analysis results, like $\mathrm{d}$ in $\mathrm{nm}$ (interspacing distance between corresponding two planes), FWHM (Full width at half maximum), $2 \theta$ in degree (peak position), and L in $\AA$ (crystalline size) of un-irradiated and irradiated with $100 \mathrm{kGy}, 375 \mathrm{kGy} \& 570 \mathrm{kGy}$ ( $\gamma$-ray) for [110] plane, of HDPE has been summarized.

\begin{tabular}{l|l|l|l|l} 
Sample name & d $(\mathbf{1 1 0}) \mathbf{~ n m}$ & FWHM & $\mathbf{2 \theta}$ (degree) & L $(\AA)$ \\
\hline Un-irradiated & 41.4339 & 0.4583 & 21.42 & 3.214 \\
\hline $100 \mathrm{kGy}$ & 41.3195 & 0.4634 & 21.48 & 3.179 \\
\hline $375 \mathrm{kGy}$ & 41.3957 & 0.4614 & 21.44 & 3.193 \\
\hline $570 \mathrm{kGy}$ & 41.2057 & 0.4682 & 21.54 & 3.147
\end{tabular}

The XRD pattern of un-irradiated and irradiated HDPE samples (Figure 3) shows that the peak broadens or FWHM increases, and estimated crystallite size $(L)$ decreases with an increase of gamma radiation dose (details in Table 1). The same results have been in the agreement of the reports [37-38]. Crystalline size $(L)$ decreases due to the $\mathrm{C}-\mathrm{H}$ bond breaking in the crystalline region and may lead to the formation of a mixture of radicals like alkyl, allyl, and polyenyl [39], observed in our FTIR data.

\subsection{UV-Visible spectroscopy measurement.}

The optical absorbance versus wavelength graphs from UV-visible absorption spectroscopy is depicted in Figure 4 for different doses up to $570 \mathrm{kGy}$. Absorbance in the nearUV has been observed to be more sensitive to $\gamma$-irradiation in the wavelength range 280-385 $\mathrm{nm}$, out of 200 to $1100 \mathrm{~nm}$ spectrum actually recorded. The absorbance of irradiated HDPE increases with an increase of gamma dose at a particular wavelength monotonically (Figure 5). The macroscopic observation of HDPE sheets, before and after irradiation, shows a change in color from white to brownish (Figure 1). This color variation is more prominent with the increase of radiation dose up to $570 \mathrm{kGy}$. It has been observed that on increasing the radiation dose with an increase in absorption, a darkening of color increases. The wavelength of maximum absorption $\left(\lambda_{\max }=337 \mathrm{~nm}\right)$ of irradiated polymer is shifted to a higher wavelength with respect to wavelength $\left(\lambda_{\max }=305 \mathrm{~nm}\right)$ of pristine HDPE, indicating a change in chemical structure. This behavior indicates the formation of a chromophore group, possibly by the formation of structures conjugated to the carbonyl group. This is due to the oxidation reaction between atmospheric oxygen and free radical created due to irradiation.

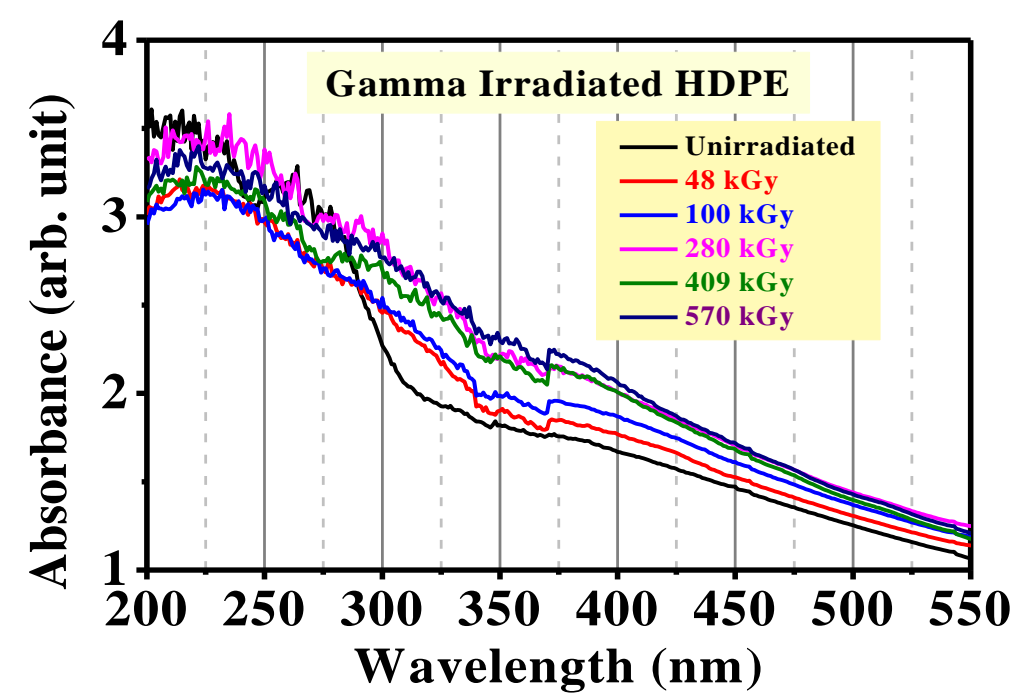

Figure 4. UV-Visible absorption spectra of virgin and irradiated HDPE sheets, with doses indicated in the figure. 


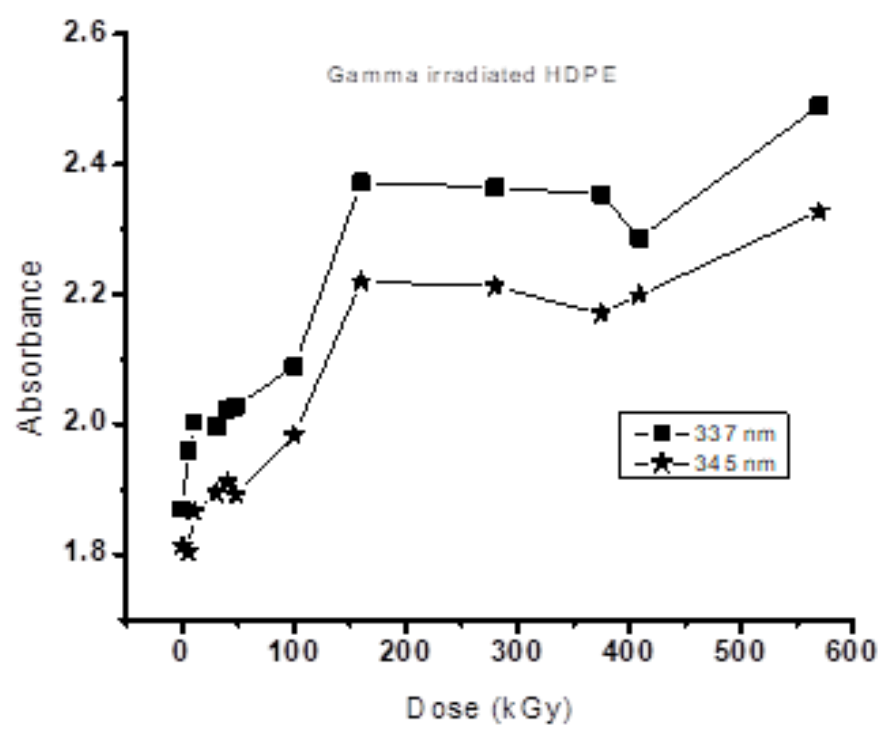

Figure 5. Optical absorbance (A) vs. radiation dose at two specific wavelengths ( $337 \& 345 \mathrm{~nm})$ for $\gamma$-irradiated HDPE.

According to Tauc and Davis-Mott model [40], the shift in absorption edge from ultraviolet towards visible region under irradiation is correlated to $\mathrm{E}_{\mathrm{g}}$ (the optical band gap energy) as follows:

$$
\alpha h v=B^{2}(h v-E g)^{n}
$$

where $\alpha=2.303 \mathrm{~A} / \mathrm{t}$, with $\mathrm{A}=$ absorbance and $\mathrm{t}=$ thickness of the sample. Also, $\alpha$ is the optical absorption coefficient, and $v=\mathrm{c} / \lambda$ is the frequency of incident photon (with $\lambda=$ wavelength $\&$ $\mathrm{c}=$ velocity of light in vacuum), $\mathrm{h}=$ Plank constant, $\mathrm{B}=$ band tailing parameter, and $\mathrm{B}$ is a constant (depending on transition probability). B has presently been assumed to be constant in the optical frequency range. Here, $\mathrm{n}$ is the transition index parameter. It may have values $(2,3$, $1 / 2$, and 1/3) implying indirect allowed, indirect forbidden, direct allowed, and directly forbidden transitions [41-42], respectively. We have calculated the values of $\mathrm{B}, \mathrm{Eg}_{\mathrm{g}}$, and $\mathrm{n}$ (as shown in table 2) using equation (1), fitting the empirical formula $y=a(x-b)^{n}$ where $a=B^{2}, x$ $=\mathrm{h} v$, and $\mathrm{b}=\mathrm{E}_{\mathrm{g}}$. Origin software has been used.

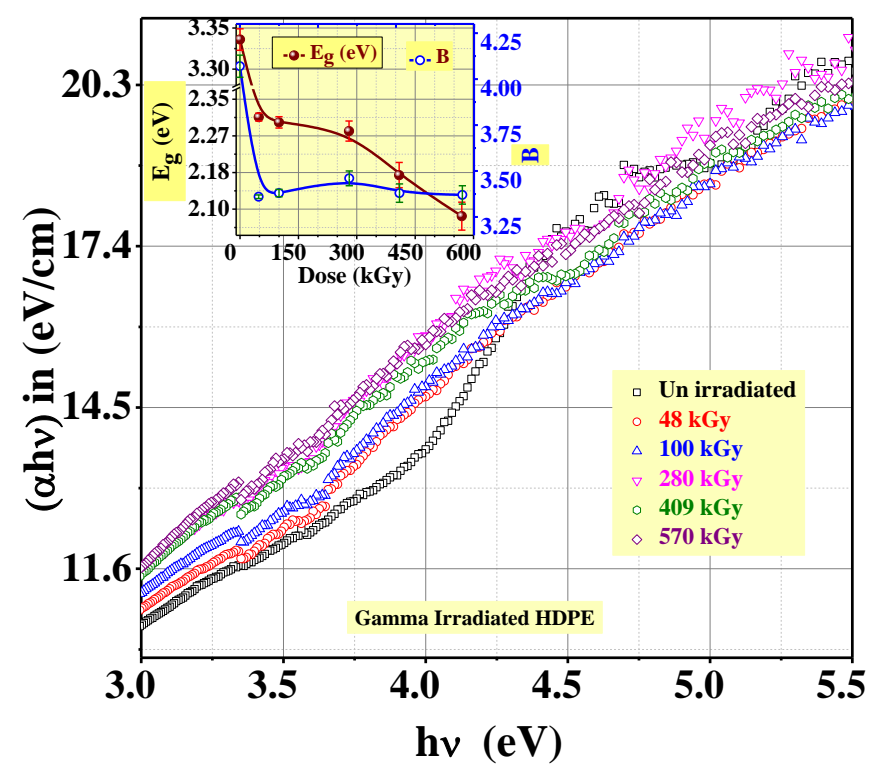

Figure 6. $(\alpha h v)$ vs. hv (incident photon energy) plots for pristine and $\gamma$-ray irradiated HDPE. (where $\alpha=$ optical absorption coefficient and $v=\mathrm{c} / \lambda=$ frequency of incident photon irradiation). The inset depicts the variation of bandgap energy $\mathrm{E}_{\mathrm{g}}$ of HDPE samples, irradiated with ${ }^{60} \mathrm{Co} \gamma$-rays. 
Irradiation must be leading to the formation of conjugated bonds (possible formation of carbon clusters). The absorption bands in the investigated range of wavelength are associated to the $\pi-\pi^{*}$ electron transition [43]. This type of transition is known in unsaturated centers of the molecules, i.e., in compounds containing double or triple bonds. In a linear structure, the number of $\mathrm{C}$-atoms per conjugation length $\mathrm{N}$ is given by $\mathrm{N}=2 \pi \beta / \mathrm{Eg}$, where $2 \beta$ is the band structure energy of a pair of adjacent $\pi$ sites and $\beta \approx 2.9 \mathrm{eV}$ as it is associated with $\pi-\pi^{*}$ optical transitions in $-\mathrm{C}=\mathrm{C}$ - structure [44].

Table 2. Compilation of Tauc and Davis-Mott model $\left[\alpha \mathrm{h} v=\mathrm{B}^{2}\left(\mathrm{~h} v-\mathrm{E}_{\mathrm{g}}\right)^{\mathrm{n}}\right]$ fit parameters like band tailing parameter $(B)$, optical band gap energy $\left(E_{g}\right)$, and energy band index parameter (here, $n=1 / 2$ for directly allowed band gap) for the HDPE samples irradiated with different gamma doses.

\begin{tabular}{l|l|l|l|l|l} 
Dose kGy & $\mathbf{B}\left(\mathbf{e V}^{\mathbf{1 / 4}} \cdot \mathbf{c m}^{\mathbf{1 / 2}}\right)$ & $\mathbf{E g}(\mathbf{e V})$ & $\mathbf{n}$ & $\mathbf{A d j} \mathbf{R}^{\mathbf{2}}$ & $\mathbf{N}$ \\
\hline 00 & $4.07 \pm 0.06$ & $3.336 \pm 0.013$ & 0.5 & 0.993 & $\sim 5$ \\
\hline 48 & $3.36 \pm 0.01$ & $2.311 \pm 0.009$ & 0.5 & 0.998 & $\sim 8$ \\
\hline 100 & $3.38 \pm 0.02$ & $2.299 \pm 0.013$ & 0.5 & 0.997 & $\sim 8$ \\
\hline 280 & $3.46 \pm 0.04$ & $2.279 \pm 0.023$ & 0.5 & 0.987 & $\sim 8$ \\
\hline 409 & $3.38 \pm 0.05$ & $2.178 \pm 0.029$ & 0.5 & 0.998 & $\sim 8$ \\
\hline 570 & $3.37 \pm 0.05$ & $2.084 \pm 0.032$ & 0.5 & 0.987 & $\sim 9$
\end{tabular}

Present polymers (HDPE) show better fit at $\mathrm{n}=1 / 2$, indicting direct bandgap transition. The bandgap decreases from $\sim 3.34 \mathrm{eV}$ (for the un-irradiated sample) to $\sim 2.08 \mathrm{eV}$ for $570 \mathrm{kGy}$ gamma radiation. The variation of $\mathrm{Eg}$ with dose can be seen in the inset of Figure 6. It is similar to the observations in PES polymer [45]. The value of B decreases from $\sim 4.07$ to $\sim 3.36$ $\mathrm{eV}^{1 / 4} \cdot \mathrm{cm}^{1 / 2}$, due to $48 \mathrm{kGy} \gamma$-ray irradiation. But for further irradiation, B remains constant. Here, $\mathrm{N}$, the corresponding number of carbon atoms per conjugation length, increases with radiation dose (Table 2).

\subsection{FTIR measurement.}

FTIR spectrum of irradiated and virgin HDPE sheets for different doses has been depicted in Figure 7. The peak value of virgin HDPE is 2914, 2846, 1471, 1461, 728, and 716 $\mathrm{cm}^{-1}$, as tabulated in Table 3. The peak at $2914 \mathrm{~cm}^{-1}$ represents anti-symmetric stretching vibration and that at $2846 \mathrm{~cm}^{-1}$ represents symmetric stretching of $\mathrm{C}-\mathrm{H}$ bond of methyl group; $1471 \mathrm{~cm}^{-1}$ and $1461 \mathrm{~cm}^{-1}$ peaks represent bending vibration of $\mathrm{C}-\mathrm{H}$ bond deformation in the plane, and $728 \mathrm{~cm}^{-1}$ represents inner rocking vibration of $-\mathrm{CH}_{2}$ - in the crystalline part and 716 $\mathrm{cm}^{-1}$ as inner rocking vibration of $-\mathrm{CH}_{2}$ - in the amorphous part of HDPE [38]. Infrared peaks were analyzed by several researchers [35-37,46-47]; peaks at 2916 and $2846 \mathrm{~cm}^{-1}$ correspond to the anti-symmetric and symmetric stretching of the $\mathrm{C}-\mathrm{H}$ bond in $-\mathrm{CH}_{2}-\mathrm{CH}_{2}$-chain. The strong peak of $1461 \mathrm{~cm}^{-1}$ found in all the samples, whether irradiated or pristine, is associated with the methylene group $\left(-\mathrm{CH}_{2}-\right)$ [44,48]. The change in the transmittance of these characteristic bands indicated that the methylene group is altered by the gamma radiation and followed the same tendency in up to the dose $570 \mathrm{kGy}$. The observed initial decrease shows that modifications occur at low doses and that the crosslinking on HDPE chains starts with the breaking of $\mathrm{C}-\mathrm{H}$ bonds [38]. It has shown that although $\mathrm{C}-\mathrm{H}$ bond energy $(4.3 \mathrm{eV})$ is higher than the bond energy of $\mathrm{C}-\mathrm{C}$ bond $(3.7 \mathrm{eV})$ in ethane molecule, under irradiation, $\mathrm{C}-\mathrm{H}$ bonds are broken more frequently than $\mathrm{C}-\mathrm{C}$ bonds [2].

On gamma irradiation, the change in the absorbance (A), $A=2-\log _{10}(\% \mathrm{~T})$ following Lambert-Beers law. This law states that absorbance is directly proportional to concentration. The increase in transmittance value for the peaks $2914,2846,1471,1461,728$, and $716 \mathrm{~cm}^{-1}$ indicates that the $\mathrm{C}-\mathrm{H}$ bond of the methylene group has been ruptured more and more with 
increasing of gamma dose up to $570 \mathrm{kGy}$. As a result, free radicals are generated in a macromolecule, which is available for further reconstruction [45,49]. In irradiated HDPE, new peaks appear at $1644 \mathrm{~cm}^{-1}$, which on further irradiation shifts to $1633 \mathrm{~cm}^{-1}$ and on still higher radiation to $1623 \mathrm{~cm}^{-1}$. This peak should correspond to $-\mathrm{C}=\mathrm{C}$ - stretching vibration [50]. This is due to the development of unsaturation groups in the irradiated polymer. The intensity of the peak at $1623 \mathrm{~cm}^{-1}$ is less, indicating that different kinds of unsaturated radicals have formed: alkyl, allyl, and polyenyl. The variation of peak value from 1644 to $1623 \mathrm{~cm}^{-1}$ suggests that a mixture of different types of radicals are formed, which are not stable and are reconstructing on irradiation. Their formation mechanism is explained further in the schematic reaction mechanism equations (number $8-10$ ). The shift in $\lambda_{\max }$ value towards higher wavelength from a pristine sample to irradiated polymer in UV-visible spectra is supporting the formation of the chromophore group. It can be clearly seen that from Figure 7, there is a small shoulder developing in the region of $1655 \mathrm{~cm}^{-1}-1753 \mathrm{~cm}^{-1}$, and it is due to the formation of some carbonyl group $(>\mathrm{C}=\mathrm{O})$ [37].

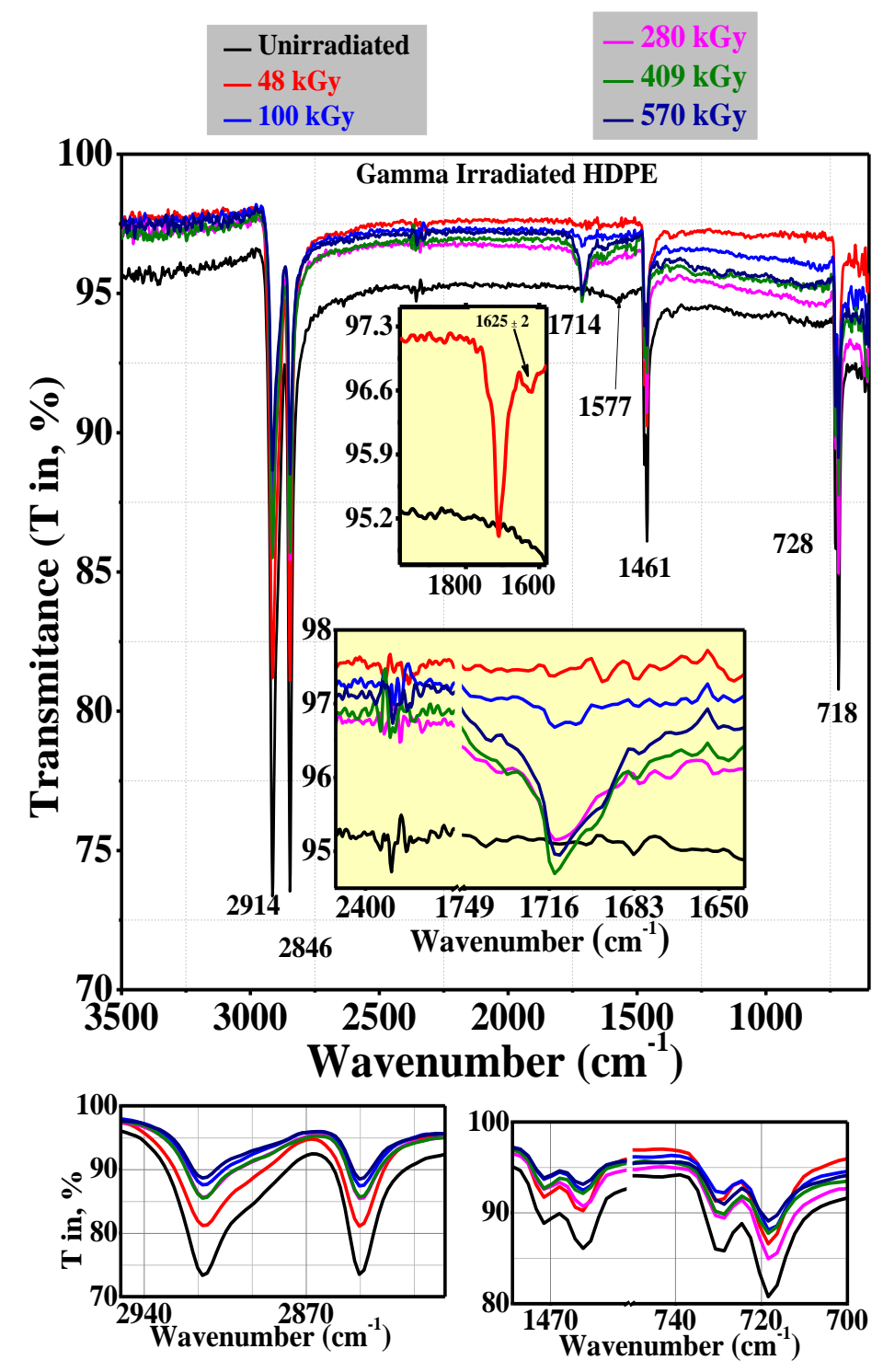

Figure 7. FTIR spectra of virgin and $\gamma$-rays irradiated HDPE sheets.

This band peak at $1714 \mathrm{~cm}^{-1}$ is attributed to the ketone carbonyl group, which is in good agreement of the reaction mechanism proposed in equation (4). A similar observation is reported [51] that the carbonyl groups at $1716 \mathrm{~cm}^{-1}$ are mainly ketone groups. The intensity of 
the $1714 \mathrm{~cm}^{-1}$ (carbonyl group) band increases with an increase in the irradiation dose due to the formation of a conjugated system of the bond as a result of bond cleavage and reconstruction. It reveals more oxidation taking place in polyethylene chains with an increase of gamma dose. The carbonyl band in the range $1655-1750 \mathrm{~cm}^{-1}$ is broadened [45] with irradiation dose as degradation products include different carbonyl group formation (ester, carboxylic acids, aldehyde, and ketone) due to rearrangement and reconstruction of macromolecule radicals [37]. It has been reported that oxidation of polyethylene takes place in irradiated polyethylene with the carbonyl group as the oxidation product [52].

Table 3. FTIR results in wavenumber $\left(\mathrm{cm}^{-1}\right)$ for pristine and irradiated HDPE.

\begin{tabular}{|c|c|c|c|c|c|c|c|}
\hline & \multicolumn{6}{|c|}{$\gamma$-ray dose } & \multirow{2}{*}{$\begin{array}{l}\text { Functional Group, Types of } \\
\text { vibration, and Ref. No. }\end{array}$} \\
\hline & Pristine & $48 k G y$ & $100 k G y$ & $280 k G y$ & $375 k G y$ & $570 k G y$ & \\
\hline Wave number & 2914 & 2914 & 2914 & 2914 & 2914 & 2914 & \multirow{2}{*}{$\begin{array}{l}v-\mathrm{CH}_{2-}, \text { Antisymmetric stretching } \\
{[5,46,48-49]}\end{array}$} \\
\hline$\%$ Trans & 0.7336 & 0.8119 & 0.8758 & 0.8561 & 0.8848 & 0.8864 & \\
\hline Wave number & 2846 & 2846 & 2846 & 2846 & 2846 & 2846 & \multirow{2}{*}{$\begin{array}{l}\mathrm{v}-\mathrm{CH}_{2-}, \quad \text { symmetric stretching } \\
{[5,46,48-49]}\end{array}$} \\
\hline$\%$ Trans & 0.7353 & 0.8109 & 0.8743 & 0.8543 & 0.8871 & 0.8850 & \\
\hline Wave number & - & - & 1714 & 1714 & 1714 & 1714 & \multirow{2}{*}{$\begin{array}{l}\mathrm{v}-\mathrm{C}=\mathrm{O}, \text { Stretching carboxylic acid } \\
\text { (ketone) }[46,49,51-52]\end{array}$} \\
\hline$\%$ Trans & 0.9510 & 0.9737 & 0.9668 & 0.9515 & 0.9575 & 0.9496 & \\
\hline Wave number & - & 1644 & 1633 & 1633 & 1623 & 16 & \multirow[t]{2}{*}{$v-\mathrm{C}=\mathrm{C}-, *$ Stretching alkene $[50]$} \\
\hline$\%$ Trans & & 0.9730 & 0.9690 & 0.9603 & 0.9700 & 0 . & \\
\hline Wave num & 1471 & 1471 & 1471 & 1471 & 1471 & 1471 & \multirow{2}{*}{$\begin{array}{l}\delta-\mathrm{CH}_{2}-\text {, Deformation in the plane } \\
\text { [53] }\end{array}$} \\
\hline$\%$ Trans & 0.8884 & 0.9170 & 0.9370 & 0.9259 & 0.9379 & 0.9383 & \\
\hline Wave number & 1461 & 1461 & 1461 & 1461 & 1461 & 1461 & \multirow{2}{*}{$\begin{array}{l}\delta-\mathrm{CH}_{2^{-}}, \text {Deformation in the plane } \\
{[44,48-49]}\end{array}$} \\
\hline$\%$ Trans & 0.8609 & 0.9023 & 0.9247 & 0.9072 & 0.9324 & 0.9314 & \\
\hline Wave nun & 728 & 728 & 728 & 728 & 728 & 728 & \multirow{2}{*}{$\begin{array}{l}\delta-\mathrm{CH}_{2}-\text {, Inner rocking vibration of } \\
-\mathrm{CH}_{2} \text { - in the crystalline part [44] }\end{array}$} \\
\hline$\%$ Trans & 0.8077 & 0.8659 & 0.8811 & 0.8495 & 0.8928 & 0.8910 & \\
\hline
\end{tabular}

* Different wave number shows a different kind of alkenes form.

\subsection{Reaction mechanism of product formation.}

Irradiation of polymers by high energy gamma rays generates free macro radical $\left(\mathrm{R}^{\mathrm{o}}\right)$ in the amorphous as well as crystalline parts of HDPE. Free radicals formed in the crystalline region are trapped, and after crystal, melting is able to recombine. The presence of an oxygen environment produces hydroperoxides $(\mathrm{ROOH})$, which is converted next into carbonyl groups $(>\mathrm{C}=\mathrm{O})$ in the subsequent reactions [41].

The mechanism of formation of the carbonyl group $(>\mathrm{C}=\mathrm{O})$ during the radiation damage process is here proposed to involve three steps: initiation stage, propagation stage, and termination stage [36]. The proposed mechanism of radiation damage of polymer is presented in the form of the following chemical reactions. Chemical reaction (1) represents the breakage of alkyl carbon-hydrogen bond in the presence of gamma rays and the formation of $\left(\mathrm{H}^{\circ}\right)$ radical. Chemical reaction (2) \& (3) represents oxidation of HDPE with atmospheric oxygen.<smiles></smiles><smiles>[3H]CCCCCCCCC</smiles><smiles>CCCCCCCCC[TeH+]OCCCCCC(CCCCC)O[O-]</smiles> 


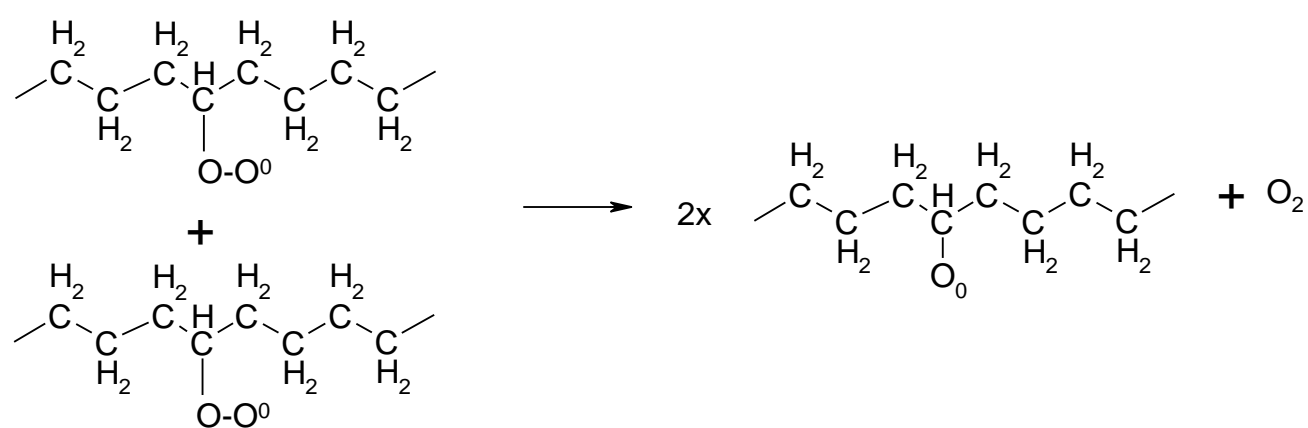

Chemical reaction (4) represents the formation of the ketonic carbonyl group and is found in our FTIR peak at $1714 \mathrm{~cm}^{-1}$. This is also in agreement with the findings reported [52]. Chemical reaction (5) represents the formation of aldehydic carbonyl group as well as chain scission of HDPE polymer.

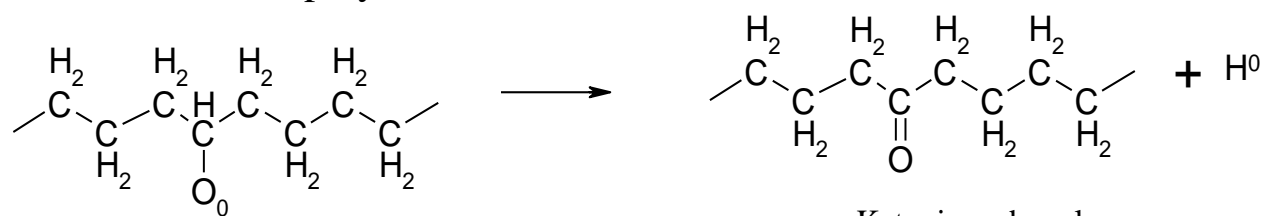

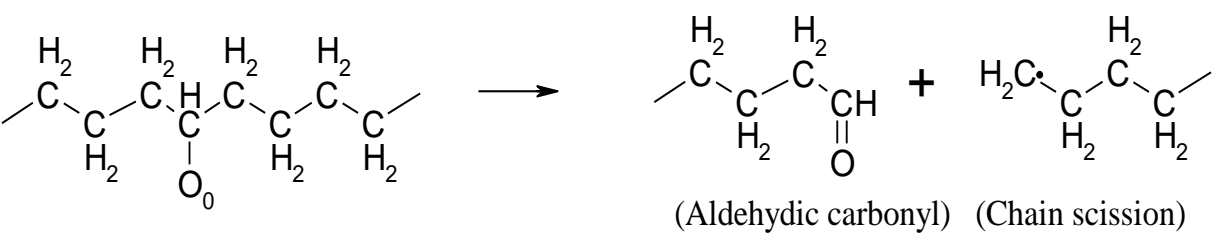

Chemical reaction (6) represents the formation of unsaturation and volatile hydrogen molecule.

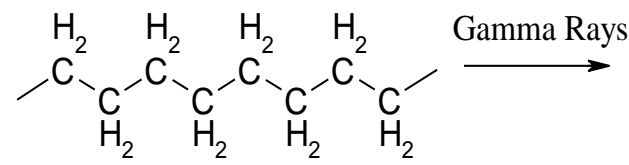<smiles>CCCCCCCCC[18O]</smiles><smiles>CCCCC=CCCC[18F]</smiles>

Chemical reactions representing the formation of the type of radical under irradiations are alkyl (7), allylic (8), and probably first time represents the structure of polyenyl radical formation \{dienyl (9) and trienyl (10) radical $\}$ molecule. In an irradiated polymer, FTIR band intensity of peaks 1644,1633 , and $1623 \mathrm{~cm}^{-1}$ are in good agreement with the formation of different types of radicals which are not stable and are reconstructing into to each other on further irradiation.<smiles>CCCCCCCCCCCCCCCCCC</smiles><smiles>[3H]CCCCCCCCC</smiles><smiles>[3H]CCCCCCCCC</smiles>

Alkyl radicals 


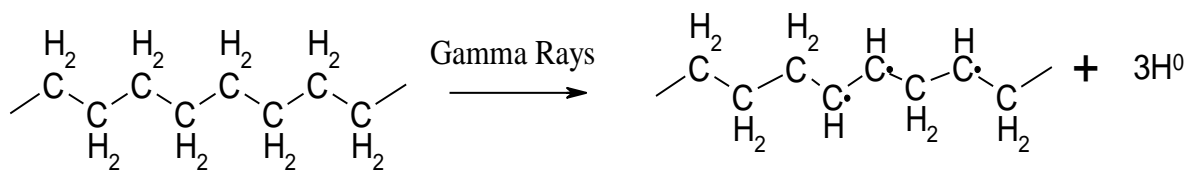

$$
\begin{aligned}
& \uparrow
\end{aligned}
$$

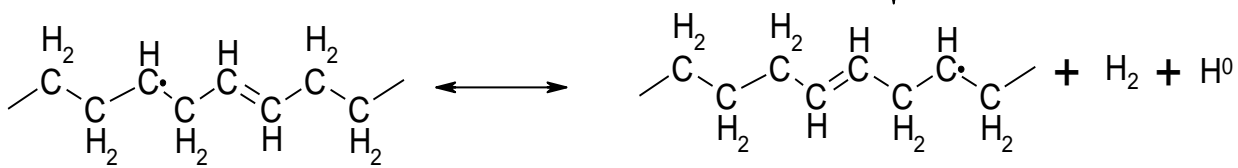

$$
\begin{aligned}
& \text { Allylic radicals }
\end{aligned}
$$

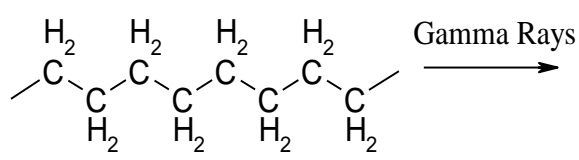

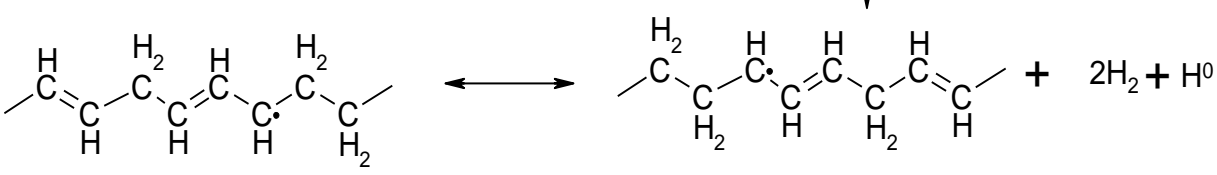

$$
\begin{aligned}
& \text { Polyenyl radical (dienyl radical) }
\end{aligned}
$$

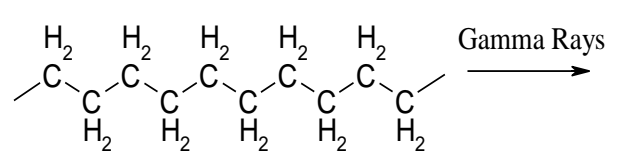

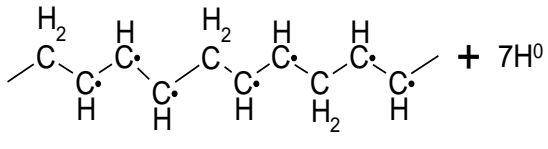

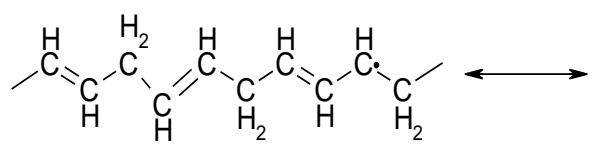

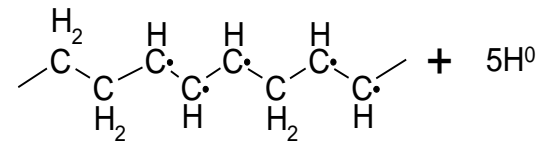

$$
\begin{aligned}
& \downarrow
\end{aligned}
$$

Chemical reaction (11) \& (12) represents the formation of crosslinking as well as the release of the small volatile hydrogen molecule in the polymer chain.

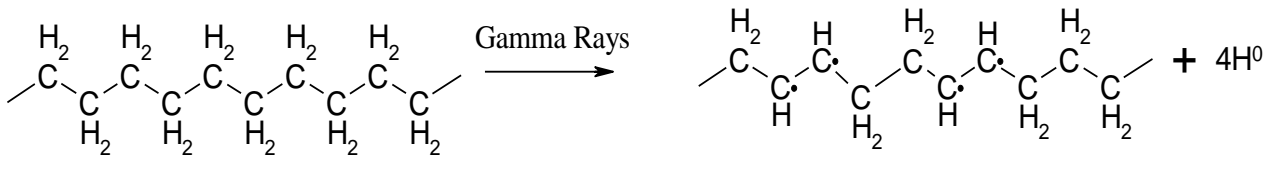

$$
\begin{aligned}
& 4 \mathrm{H}^{0} \longrightarrow 2 \mathrm{H}_{2}
\end{aligned}
$$<smiles>CCCCCCCCCCCC</smiles><smiles>CCCCCCCCCCCC</smiles><smiles>CCCCCC1CCCC(CC)C(CCC)C2CCC(C(CCC)C(CCCC)CCCC(CCC)C1CCC)C2CCC</smiles><smiles>CCCCCCCCCCCC</smiles>

Cross-linking

Researchers [36, 54] attributed the new band in the irradiated (dose $2000 \mathrm{kGy}$ ) polymer to the reaction of $\mathrm{OH}$ group with polymer matrix, with the production of some oxidative compounds like- carboxylic acids, alcohols, esters, and ketones. Fourier Transform InfraredPhotoacoustics Spectroscopy (FTIR-PAS) study shows that irradiation could introduce groups 
like $-\mathrm{C}=\mathrm{O}$, -O-C-O-, O=C-O- into HDPE [55]. Chemical reaction (13) \& (14) represents the formation of carboxylic and ester carbonyl group in the irradiated polymer chain.

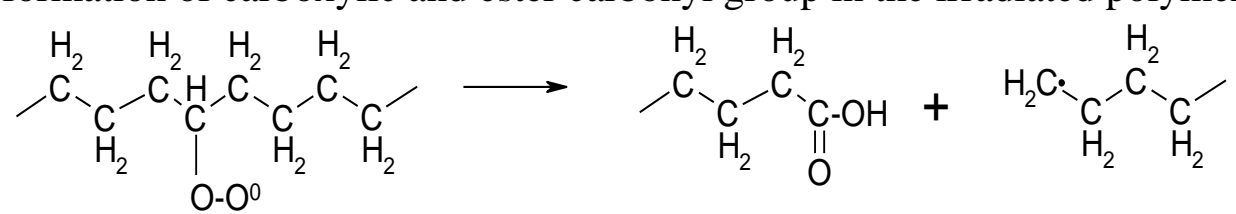

Carboxylic carbonyl

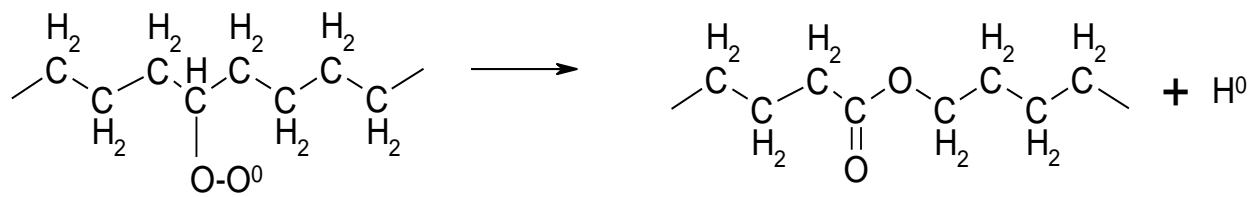

Ester carbonyl

Chemical reaction (15) represents the formation of the alcohol group in the irradiated polymer chain.

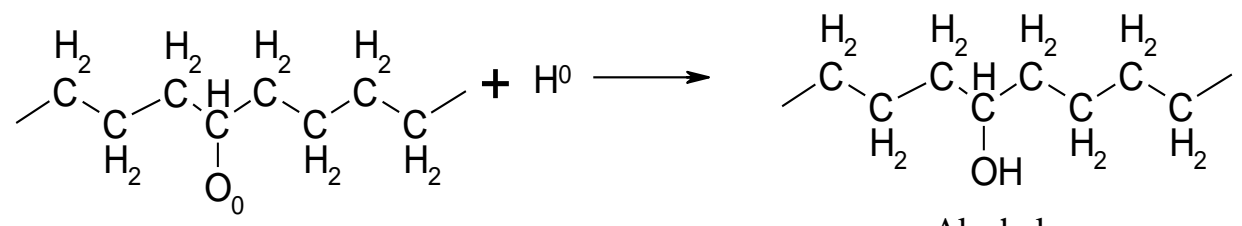

Alcohol

\section{Conclusions}

The degradation reaction mechanism of the irradiated polymer has been investigated. The change of absorbance, even at the lowest dose of $\gamma$-irradiation, is detected by UV-Vis spectroscopy. HDPE degradation process involves crosslinking at lower doses up to $570 \mathrm{kGy}$. Bathochromic shift $(\sim 30 \mathrm{~nm})$ in the irradiated polymer is observed. Visually observed coloring of the almost colorless HDPE sample on irradiation to the brown can be due to an increase in the number of conjugation in the irradiated polymer. The optical band gap energy decreases with $\gamma$-irradiation. FTIR results show that unsaturated radicals and ketone-carbonyl groups $(>\mathrm{C}=\mathrm{O})$ are formed. The carbonyl concentration increases with the irradiation dose. Mechanism of product formation chemistry of unsaturated (alkyl, allyl, and polyenyl) radicals, chain scission, crosslinking, and carbonyl group generation have been discussed. The gamma irradiation in the air induces carbonyl formation, accompanied by a break-up of the $\mathrm{C}-\mathrm{H}$ bond of methylene group rather than a $\mathrm{C}-\mathrm{C}$ bond of $-\mathrm{H}_{2} \mathrm{C}-\mathrm{CH}_{2}-\mathrm{C}-\mathrm{H}$ bond breaking and reconstruction generate network structure. Gamma irradiation up to $570 \mathrm{kGy}$ of HDPE in the air causes crosslinking more rather than chain scission and induces photooxidative degradation. This modifies the molecular structure of the material. Variations of the parameters in the Tauc and Davis-Mott model and bandgap due to our $\gamma$-ray irradiation have been discussed on the basis of our experimental results.

\section{Funding}

The authors thankful to Prof. M.K. Singh, Director, UPTTI, Kanpur, and Prof. Prashant, Coordinator, TEQIP-III Program, Govt. of India, for providing financial support. 


\section{Acknowledgments}

The corresponding author thankful to the Department of Chemistry, HBTU, Kanpur, for providing necessary facilities and the UGC-DAE CSR Kolkata center for the gamma irradiation facility.

\section{Conflicts of Interest}

The authors declare no conflict of interest.

\section{References}

1. O’Donnell, J.H.; Sangester, D.F. Principles of radiation chemistry. Arnold, E. (Publishers) Ltd., London, 1970.

2. Chapiro, A. Chemical modifications in irradiated polymers. Nuclear Instruments and Methods in Physics Research Section B: Beam Interactions with Materials and Atoms 1988, 32, 111-114, https://doi.org/10.1016/0168-583X(88)90191-7

3. Dorey, S.; Gaston, F.; Girard-Perier, N.; Dupuy, N.; Marque, S.R.A.; Delaunay, L. Generation of O2Permeation Barrier during the Gamma-Irradiation of Polyethylene/Ethylene-Vinyl Alcohol/Polyethylene Multilayer Film. Industrial \& Engineering Chemistry Research 2019, 58, 14115-14123, https://doi.org/10.1021/acs.iecr.9b02145

4. Davenas, J.; Stevenson, I.; Celette, N.; Cambon, S.; Gardette, J.L.; Rivaton, A.; Vignoud, L. Stability of polymers under ionising radiation: The many faces of radiation interactions with polymers. Nuclear Instruments and Methods in Physics Research Section B: Beam Interactions with Materials and Atoms 2002, 191, 653-661, https://doi.org/10.1016/S0168-583X(02)00628-6

5. Prasad, S.G.; De, A.; De, U. Structural and Optical Investigations of Radiation Damage in Transparent PET Polymer Films. International Journal of Spectroscopy 2011, 2011, 1-7, https://doi.org/10.1155/2011/810936.

6. Singh, P.; Kumar, R. Radiation Physics and Chemistry of Polymeric Materials. In:Radiation Effects in Polymeric Materials. Kumar, V.; Chaudhary, B.; Sharma, V.; Verma, K.; Eds. Springer International Publishing: Cham, 2019; https://doi.org/10.1007/978-3-030-05770-1_2

7. Chapiro, A. General consideration of the radiation chemistry of polymers. Nuclear Instruments and Methods in Physics Research Section B: Beam Interactions with Materials and Atoms 1995, 105, 5-7, https://doi.org/10.1016/0168-583X(95)00861-6

8. Aggarwal, S.; Sajwan, M.; Singh, R. Crystallinity of HDPE Pipes by DSC, XRD and FTIR Spectroscopy A Forensic Comparison. Indian Journal of Criminology and Criminalistics 2008, 29, 141-148.

9. Moise, I.V.; Manea, M.M.; Vasilca, S.; Pintilie, C.; Virgolici, M.; Cutrubinis, M.; Stanculescu, I.R.; Meltzer, V. The crosslinking behaviour of cellulose in gamma irradiated paper. Polymer Degradation and Stability 2019, 160, 53-59, https://doi.org/10.1016/j.polymdegradstab.2018.12.005

10. Burg, K.J.L.; Shalaby, S.W. Radiation Sterilization of Medical Devices and Pharmaceuticals. In:Irradiation of Polymers. American Chemical Society: 1996; 620, 240-245, https://doi.org/10.1021/bk-19960620.ch018.

11. Ojha, N.; Pradhan, N.; Singh, S.; Barla, A.; Shrivastava, A.; Khatua, P.; Rai, V.; Bose, S. Evaluation of HDPE and LDPE degradation by fungus, implemented by statistical optimization. Scientific Reports 2017, 7, https://doi.org/10.1038/srep39515.

12. Goulas, A.E.; Riganakos, K.A.; Badeka, A.; Kontominas, M.G. Effect of ionizing radiation on the physicochemical and mechanical properties of commercial monolayer flexible plastics packaging materials. Food Additives \& Contaminants 2002, 19, 1190-1199, https://doi.org/10.1080/0265203021000012402.

13. Liu, Q.; Liu S.; Lv, Y.; Huang Y.; Kong M.; Yang Q.; Li G. Photo-degradation of polyethylene under stress: A successive self-nucleation and annealing (SSA) study. Polymer Degradation and Stability, 2020, 172, 109060, https://doi.org/10.1016/j.polymdegradstab.2019.109060.

14. Suarez, J.C.M.; da Costa Monteiro, E.E.; Mano, E.B. Study of the effect of gamma irradiation on polyolefins-low-density polyethylene. Polymer Degradation and Stability 2002, 75, 143-151, https://doi.org/10.1016/S0141-3910(01)00213-0.

15. Smedberg, A.; Hjertberg, T.; Gustafsson, B. Crosslinking reactions in an unsaturated low density polyethylene. Polymer 1997, 38, 4127-4138, https://doi.org/10.1016/S0032-3861(96)00994-9.

16. Pelto, J.; Verho, T.; Ronkainen, H.; Kaunisto, K.; Metsäjoki, J.; Seitsonen, J.; Karttunen, M. Matrix morphology and the particle dispersion in HDPE nanocomposites with enhanced wear resistance. Polymer Testing, 2019, 77, 105897, https://doi.org/10.1016/j.polymertesting.2019.105897. 
17. Amoroso, L.; Heeley, E.L.; Ramadas S.N.; McNally, T. Crystallisation behaviour of composites of HDPE and MWCNTs: The effect of nanotube dispersion, orientation and polymer deformation, Polymer, 2020, 201, 122587, https://doi.org/10.1016/j.polymer.2020.122587.

18. Nabiyev, A.A.; Olejniczak, A. ; Pawlukojc, A.; Balasoiu, M.; Bunoiu, M.; Maharramov, A.M.; Nuriyev, M.A.; Ismayilova, R.S. ; Azhibekov, A.K.; Kabyshev, A.M.; Ivankov, O.I. ; Vlase, T.; Linnik, D.S.; Shukurova, A.A.; Ivanshina, O.Y.; Turchenko, V.A.; Kuklin, A.I. Nano-ZrO2 filled high-density polyethylene composites: Structure, thermal properties, and the influence $\gamma$-irradiation. Polymer Degradation and Stability, 2020, 171, 109042, https://doi.org/10.1016/j.polymdegradstab.2019.109042.

19. Salasinska K.; Mizera K.; Celiński M.; Kozikowski P.; Borucka M.; Gajek, A. Thermal properties and fire behavior of polyethylene with a mixture of copper phosphate and melamine phosphate as a novel flame retardant. Fire Safety Journal, 2020, 115, 103137, https://doi.org/10.1016/j.firesaf.2020.103137.

20. Fouad, H.; Elleithy, R. High density polyethylene/graphite nano-composites for total hip joint replacements: Processing and in vitro characterization. Journal of the Mechanical Behavior of Biomedical Materials 2011, 4, 1376-1383, https://doi.org/10.1016/j.jmbbm.2011.05.008.

21. Alothman, O.Y.; Fouad, H.; Al-Zahrani, S.M.; Eshra, A.; Al Rez, M.F.; Ansari, S.G. Thermal, creeprecovery and viscoelastic behavior of high density polyethylene/hydroxyapatite nano particles for bone substitutes: effects of gamma radiation. BioMedical Engineering OnLine 2014, 13, https://doi.org/10.1186/1475-925X-13-125.

22. Wang, S.; Zhang, J. Non-isothermal crystallization kinetics of high density polyethylene/titanium dioxide composites via melt blending. Journal of Thermal Analysis and Calorimetry 2014, 115, 63-71, https://doi.org/10.1007/s10973-013-3241-X.

23. Li Y.; He H.; Ma Y.; Geng Y.; Tan J. Rheological and mechanical properties of ultrahigh molecular weight polyethylene/high density polyethylene/polyethylene glycol blends. Advanced Industrial and Engineering Polmer Research, 2019, 2(1), 51-60, https://doi.org/10.1016/j.aiepr.2018.08.004.

24. Amjadi M.; Fatemi A. Creep and Fatigue Behaviors of High-Density Polyethylene (HDPE): Effects of Temperature, Mean Stress, Frequency, and Processing Technique. International Journal of Fatigue, 2020, 105871, https://doi.org/10.1016/j.ijfatigue.2020.105871.

25. Nezafat, P.; Jafari, S.H.; Khonakdar, H.A; Gohs U.; Jehnichen, D. Experimental analysis and mechanical modeling of effect of stress-relaxation on shape memory and recovery behavior of e-beam irradiated HDPE, Radiation Physics and Chemistry, 2020, 168, 108568, https://doi.org/10.1016/j.radphyschem.2019.108568.

26. Awad, A.H.; Aly Abd El-Wahab, A.; El-Gamsy, R.; Abdel-latif, M.H. A study of some thermal and mechanical properties of HDPE blend with marble and granite dust. Ain Shams Engineering Journal 2019, 10, 353-358, https://doi.org/10.1016/j.asej.2018.08.005.

27. Alsayed, Z.; Awad, R.; Badawi, M.S. Thermo-mechanical properties of high density polyethylene with zinc oxide as a filler. Iranian Polymer Journal 2020, 29, 309-320, https://doi.org/10.1007/s13726-020-00796-7.

28. Li, D.; Zhou, L.; Wang, X.; He, L.; Yang, X. Effect of Crystallinity of Polyethylene with Different Densities on Breakdown Strength and Conductance Property. Materials 2019, 12, https://doi.org/10.3390/ma12111746.

29. Sinha, D. Structural Modifications of Gamma Irradiated Polymers: An FT-IR Study. Advances in Applied Science Research 2012, 3, 1365-1371.

30. Zoepfl, F.J.; Markovic̀, V.; Silverman, J. Differential scanning calorimetry studies of irradiated polyethylene: I. Melting temperatures and fusion endotherms. Journal of Polymer Science: Polymer Chemistry Edition 1984, 22, 2017-2032, https://doi.org/10.1002/pol.1984.170220907

31. Wang, W.; Zhang, X.; Mao, Z.; Zhao, W. Effects of gamma radiation on the impact strength of polypropylene (PP)/high density polyethylene (HDPE) blends. Results in Physics 2019, 12, 2169-2174, https://doi.org/10.1016/j.rinp.2019.02.020

32. Suljovrujić, E.; Stamboliev, G.; Kostoski, D. Dielectric relaxation study of gamma irradiated oriented lowdensity polyethylene. Radiation Physics and Chemistry 2003, 66, 149-154, https://doi.org/10.1016/S0969806X(02)00284-0

33. Skoog, D.A.; West, D.M.; Holler, F.J.; Crouch, S.R. Chapter 24-Introduction to Spectrochemical Methods.In: Fundamentals of Analytical Chemistry. $9^{\text {th }}$, Ninth Edition published by Brooks/Cole, 20 Davis Drive, Belmont, CA 94002-3098, USA, 2014; pp. 658.

34. Gupta, S.K.; Singh, P.; Kumar, R.; Kumar, S. Gamma Radiation Induced Modifications on Physicochemical Properties of Makrofol (KG and N) Polycarbonate. Advances in Polymer Technology 2015, 34, 2510-2516, https://doi.org/10.1002/adv.21510

35. Rahi, S.K.; Hassan, E.S.; Abd, A.N. Spectroscopic Methods Studies in Polymer.World Scientific News 2016, 42, 41-53.

36. Sinha, D.; Swu, T.; Tripathy, S.P.; Mishra, R.; Dwivedi, K.K.; Fink, D. Spectroscopic and thermal studies of gamma irradiated polypropylene polymer. Radiation Effects and Defects in Solids 2003, 158, 531-538, https://doi.org/10.1080/1042015031000074101 
37. Zaki, M.F.; Elshaer, Y.H.; Taha, D.H. The alterations in high density polyethylene properties with gamma irradiation. Radiation Physics and Chemistry 2017, 139, 90-96, https://doi.org/10.1016/j.radphyschem.2017.02.058

38. Suarez, J.C.M.; Monteiro, E.E.d.C.; Biasi, R.S.d.; Mano, E.B. Experimental Investigation of the Properties of High-Density Polyethylene after Gamma Irradiation. Journal of Polymer Engineering 2003, 23, 95-118, https://doi.org/10.1515/POLYENG.2003.23.2.95

39. Forster, A.L.; Tsinas, Z.; Al-Sheikhly, M. Effect of Irradiation and Detection of Long-Lived Polyenyl Radicals in Highly Crystalline Ultra-High Molar Mass Polyethylene (UHMMPE) Fibers. Polymers 2019, 11(5), 924, https://doi.org/10.3390/polym11050924

40. Tauc, J.; Grigorovici, R.; Vancu, A. Optical Properties and Electronic Structure of Amorphous Germanium. Physica status solidi (b) 1966, 15, 627-637, https://doi.org/10.1002/pssb.19660150224

41. Higazy, A.A.; Hussein, A. Optical absorption studies of $\gamma$ irradiated magnesium phosphate glasses. Radiation Effects and Defects in Solids 1995, 133, 225-235, https://doi.org/10.1080/10420159508223993

42. Sindhu, S.; Sanghi, S.; Agarwal, A.; Seth, V.P.; Kishore, N. Structural, optical, physical and electrical properties of V2O5.SrO-B2O3 glasses. Spectrochimica Acta Part A: Molecular and Biomolecular Spectroscopy 2006, 64, 196-204, https://doi.org/10.1016/j.saa.2005.06.039

43. Kumar, R.; Virk, H.S.; Verma, K.C.; De, U.; Saha, A.; Prasad, R. Physico-chemical modifications induced in Makrofol-N polycarbonate by swift heavy ions. Nuclear Instruments and Methods in Physics Research Section B: Beam Interactions with Materials and Atoms 2006, 251, 163-166, https://doi.org/10.1016/j.nimb.2006.06.003

44. Fink, D.; Klett, R.; Chadderton, L.T.; Cardoso, J.; Montiel, R.; Vazquez, H.; Karanovich, A.A. Carbonaceous clusters in irradiated polymers as revealed by small angle X-ray scattering and ESR. Nuclear Instruments and Methods in Physics Research Section B: Beam Interactions with Materials and Atoms 1996, 111, 303314, https://doi.org/10.1016/0168-583X(95)01433-0

45. Ahmed, B.; Raghuvanshi, S.K.; Siddhartha; Srivastava, A.K.; Krishna, J.B.M.; Wahab, M. Optical and structural study of aromatic polymers irradiated by gamma radiation. Indian Journal of Pure and Applied Physics 2012, 50, 892-898.

46. Gaston, F.; Dupuy, N.; Marque, S.R.A.; Barbaroux, M.; Dorey, S. FTIR study of ageing of $\gamma$-irradiated biopharmaceutical EVA based film. Polymer Degradation and Stability 2016, 129, 19-25, https://doi.org/10.1016/j.polymdegradstab.2016.03.040

47. Jung, M.R.; Horgen, F.D.; Orski, S.V.; Rodriguez C, V.; Beers, K.L.; Balazs, G.H.; Jones, T.T.; Work, T.M.; Brignac, K.C.; Royer, S.-J.; Hyrenbach, K.D.; Jensen, B.A.; Lynch, J.M. Validation of ATR FT-IR to identify polymers of plastic marine debris, including those ingested by marine organisms. Marine Pollution Bulletin 2018, 127, 704-716, https://doi.org/10.1016/j.marpolbul.2017.12.061

48. Yeom, B.; Yu, Y.J.; McKellop, H.A.; Salovey, R. Profile of oxidation in irradiated polyethylene. Journal of Polymer Science Part A: Polymer Chemistry 1998, 36, 329-339, https://doi.org/10.1002/(SICI)10990518(19980130)36:2<329::AID-POLA16>3.0.CO;2-Q

49. Albano, C.; Perera, R.; Silva, P.; Sánchez, Y. Characterization of Gamma IrradiatedPEs using ESR, FTIR and DSC Techniques. Polymer Bulletin 2003, 51, 135-142, https://doi.org/10.1007/s00289-003-0206-4

50. Pavia, D.L.; Lampman, G.M.; Kriz, G.S.; Vyvyan, J.R. Hydrocarbons: Alkanes, Alkenes, and Alkynes. In:Introduction to Spectroscopy. $4^{\text {th }}$ Edition, published by Brooks/Cole, 10 Davis Drive, Belmont, CA 940023098, USA, 2009; pp. 33.

51. Cardoso, E.C.L.; Scagliusi, S.R.; Parra, D.F.; Lugão, A.B. Gamma-irradiated crosslinked LDPE foams: Characteristics and properties. Radiation Physics and Chemistry 2013, 84, 170-175, https://doi.org/10.1016/j.radphyschem.2012.06.023

52. Abou Zeid, H.M.; Ali, Z.I.; Abdel Maksoud, T.M.; Khafagy, R.M. Structure-property behavior of polyethylene exposed to different types of radiation. Journal of Applied Polymer Science 2000, 75, 179-200, https://doi.org/10.1002/(SICI)1097-4628(20000110)75:2<179::AID-APP1>3.0.CO;2-B

53. Djebara, M.; Stoquert, J.P.; Abdesselam, M.; Muller, D.; Chami, A.C. FTIR analysis of polyethylene terephthalate irradiated by MeV He+. Nuclear Instruments and Methods in Physics Research Section B: Beam Interactions with Materials and Atoms 2012, 274, 70-77, https://doi.org/10.1016/j.nimb.2011.11.022

54. Phukan, T.; Kanjilal, D.; Goswami, T.D.; Das, H.L. Study of optical properties of swift heavy ion irradiated PADC polymer. Radiation Measurements 2003, 36, 611-614, https://doi.org/10.1016/S13504487(03)00210-5

55. Ding, Y.; Shi, T.; Zhang, Z.; Hu, K. Modification of HDPE by $\gamma$ ray radiation in oxygen atmosphere and blend with PA6. Journal of Radiation Research and Radiation Processing 2002, 20, 265-270. 